\title{
3D FEM Model on the Parameters' Influence of EPB-TBM on Settlements of Single and Twin Metro Tunnels During Construction
}

\author{
Masoud Forsat $^{1}$ (D) Mohammad Taghipoor $^{2} \cdot$ Masoud Palassi $^{3}$
}

Received: 24 June 2020 / Revised: 8 April 2021 / Accepted: 13 April 2021 / Published online: 23 June 2021

(c) The Author(s) 2021

\begin{abstract}
The present research exposes the investigation on three-dimensional modeling of the single and twin metro tunnels for the case of the Tehran metro line. At first, simulation implemented on the comparison of the ground movements in the single and twin tunnels. Then the simulation has been performed on the influence of effective parameters of EPB-TBM on the surface settlements throughout excavation. The overcutting, shield conicity, grouting, and the final lining system modeled and the influence of face supporting pressure, grout injection pressure, as well as the clear distance of the tunnels, has been analyzed. The initial results showed a valid ground settlement behavior. The maximum settlements occurred at the end of the shield tail and it was higher in the single tunnel. The face supporting pressure had more effect on the surface settlement in comparison to the grout injection pressure. By increasing the face pressure in the single tunnel, the place of maximum settlement moved back while the grout pressure is insignificant for decreasing the settlements. Furthermore, the influence of the clear distance in the twin tunnels led to zero after the length of $30 \mathrm{~m}$. Accordingly, for more distances, the tunnels must be examined independently and as two different single tunnels.
\end{abstract}

Keywords Twin tunnels $\cdot$ 3D modeling $\cdot$ Finite element $\cdot$ Metro tunnel $\cdot$ Numerical method $\cdot$ Plaxis

\section{Introduction}

The rapid increase rate of the population in cities and urban areas has developed the transportation methods such as subways around the world [1-5]. Most of the subways tunnels are excavated by the tunnel boring machine (TBM) for the direct line sections and some stations due to its safety, small disturbance area, high effective, low cost, and low excavating volume in comparison to the other methods $[6,7]$. In recent years, the use of TBM has been widened around the world and Earth Pressure Balance- Tunnel Boring Machine (TBM-EPB) is one of them among a lot of different types of these machines [8-10]. Earth Pressure Balanced (EPB) TBMs were introduced about 40 years ago as an excavation

Masoud Forsat

masoudforsatlar@gmail.com

1 Department of Mechanical and Industrial Engineering, Qatar University, P.O. Box 2713, Doha, Qatar

2 Department of Civil and Environmental Engineering, Tarbiat Modares University, Tehran, Iran

3 School of Civil Engineering, Department of Engineering, University of Tehran, Tehran, Iran method for fine aggregate soils [11]. However, by further development, this machine used in more types of soils like fine aggregates, coarse aggregates (gravels and sands), and hard rocks $[12,13]$. The simulation methods are used for high-efficiency working and performance prediction of the machine in the projects. Three-Dimensional modeling on the deformation of subway tunnels caused by EPB tunneling on the above and down of Shanghai subway has been investigated for predicting the soil displacements during construction. The results showed a good correlation with the field monitoring data and predicted values of the simulation [14]. Twin tunnels have many advantages including controlling the soil movements and reduces stresses in the linings [15, 16]. Due to the specification of these two types of tunnel and their application method, comparison of them is essential for describing the performance and their effects on the soil and ground movements. Hence, a lot of studies have been proposed on the settlements and movements of the soils caused by tunneling [17]. With any excavation in the ground, the in situ stress will be disturbed [18] and it causes displacements of soil and surface. Moreover, the adjacent underground spaces have interaction between each other and they should be assumed and performed together $[19,20]$. Thus 
the twin tunnels have effects on the soil displacement in a different way of two single tunnels that called closely-spaced tunnels [21,22]. Therefore the effect of the tunnel type on the ground should be investigated for predicting the ground displacements before starting the constructions.

In earlier studies, researchers have presented many investigations in the effect of tunneling on the soil movement by 2D and 3D numerical and analytical methods to simulate the tunnel excavation procedure and TBM. Mroueh et al. [23] presented a simplified 3D numerical model for predicting the soil movements caused by the tunneling with TBM. They used two coefficients for optimization which are the length of the unlined zone and the released partial stress. The study results were acceptable just for the shallow tunnel in the soft soils. Also, the simulation of the twin circular tunnels on the two and three-layered formation has been conducted by Chu et al. [24]. The strain and displacement around the tunnel caused by the excavation have been measured. The results of the simulation had a 2-4\% error with the monitored values of the construction. Also, they showed that by considering initial stress, the module of ratio, and the coefficient of earth pressure (K), the major displacements occur at the location of major stresses.

Moreover, some researchers have presented studies on the parallel tunnels in the case of tunnels size, face lagging distance, face pressure, and ground situations [25-27]. In most of these studies, the parameters of ground settlement and surface displacements have considered as the main criteria. Fang et al. [28] investigated the effect of the geometric arrangement of the closely-spaced twin tunnels on the ground settlements. The results showed an increase in surface settlements in the shallow tunnels and also they showed the possibility of settlement controlling by the construction of deeper twin tunnels,. In regarding the tunnels lagging distance, Chen et al. [29] used iterative Fourier transformation via the Schwarz alternating method to find the complex potentials of liners, geomaterial, stress, and displacement. Then they compared these parameters with the numerical case and they found that the lagging of tunnels has a great impact on the soil displacements. But with considering space 6 times larger than the radius and more, the interaction between the twin tunnels disappeared and they acted as two single tunnels. As general, the structural forces and lining displacement caused by the simultaneous excavation of twin tunnels are much less than those in the construction with the lagging distance [25]. Do et al. [30] proposed a 3D numerical investigation on the lagging distance of twin tunnel construction and showed that the critical situation for stability will appear when the face of the following tunnel stands at the transverse section of the front tunnel. The 3D finite element investigation on the effect of EPB-TBM parameters on the ground settlements caused by twin tunnel excavation of Shiraz metro has been done by Afifipour et al.
[31]. The face pressure, grout pressure, and thrust jack force have been studied. The results showed complicated relation between interaction of twin tunnels and near structures, and the face pressure of TBM has a more significant effect on the soil movements around the excavation area rather than the grout pressure and jack force. Also, Fargnoli et al. [32] studied the effects of twin tunnel excavation of Milan metro on the surface settlements. The results showed that by the construction of the second tunnel, the settlement above the first tunnel axis will increase and it is different from the superposition of two single tunnels. Although they showed that these movements will affect by the EPB parameters, no relationship has been found between the settlements above the first tunnel and excavation parameters of EPB.

Although the simulation can be used for any sections of the machine such as cutter head, the applied force, and chamber temperature [33-35], it can be used to simulate total movement during excavation of the machine. The 3D simulation on the mechanized excavation of TBM-EPB for its overall processes has been done in many studies. In most of these studies, the comparison study has been done between the ground displacements obtained from the simulation and in situ data as a controller parameter [36-40]. In the design stages of the subways maybe the type of tunnel as a single or twin tunnel is the most important parameter. In the past, most of the tunnels were excavated in a single tunnel type [41], but nowadays there are a lot of metro lines excavated as twins for different purposes [15, 42, 43]. A lot of studies have investigated the modeling of the tunnel excavating by TBM, but 3D simulation on the comparison of the soil movements caused by single and twin tunnels is inevitable before implementation.

In this study, the comparison of the single and twin tunnels has been studied. Also, the effect of different parameters of EPB-TBM machine on the soil stresses and ground settlements has been studied for in-situ monitoring throughout the implementation. The purpose of the study at the first is deciding the best plan of tunneling among single and twin tunnels and the second, assessment of the most efficient parameters of excavation on the soil displacements. The study has been done based on the case of Tehran metro line 7. Tehran Metro Line 7 is around $27 \mathrm{~km}$ length with 25 station[44] and consist of two parts which is an east-west part that is following by the south-north part. The investigated section is located at the east-west part of this line between the stations of A7 and N7. The costs analysis has been done for the tunnels based on the local prices presented by country. In this case, the diameter of the single tunnel and twin tunnel has been considered $9 \mathrm{~m}$ and $6 \mathrm{~m}$ respectively.

The void between the tunnel perimeter and segment rings was grouted by means of two-component grouting material. The grout was modeled as a thin elastic layer behind the lining system with a thickness of $2 \mathrm{~cm}$. Also, in order to 
consider the grout pressure, a spherical pressure was considered around the linings toward the border.

With the focusing on the excavation stage and using Life-Cycle Cost Analysis method [45, 46], the TBM excavation price showed 2.0 million dollar for the single tunnel which has located in the depth of $15 \mathrm{~m}$ underground and this amount for the twin tunnel with the depth of $10 \mathrm{~m}$ was 1.9 million dollars per kilometer. Although the cost analysis on the tunnels shows no difference between single and twin tunnel, some other parameters such as safety, ventilation, and level of service, should be taken to account for better serviceability.

\section{Three-Dimensional Numerical Model}

The finite element methodology and nonlinear modeling have been presented throughout the previous studies [47-49]. In this study, a contribution will be given to the modeling of EPB-TBM with the help of PLAXIS 3D Tunnel finite element software to simulate the soil movements and stresses induced by tunnels excavation. The study is intended to discuss the influence of the effective parameters of the excavating procedure including soil characteristics, TBM parameters, and tunnels position. Since the Finite Elements (FE)-mesh coarseness of the model is important and it has some effects on the results $[50,51]$. the 15 -node triangular element used for simulating soil behavior in the model. The dimension of the model is one of the important parameters that should be as wide as to have no effects on the tunnel excavation simulating. Lambrughi et al. [36] proposed the dimension of $\mathrm{H}+4 \mathrm{D}, 2(\mathrm{H}+4 \mathrm{D})$, and $2(\mathrm{H}+4 \mathrm{D})$ for height, length, and wide respectively, where the $\mathrm{H}$ is the depth of tunnel and $\mathrm{D}$ is the diameter. In this study, considering the
Table 1 The peripheral soil specification of the model

\begin{tabular}{lll}
\hline Parameters & Unit & Value \\
\hline Cohesive $(\mathrm{c})$ & $\mathrm{kPa}$ & 15.0 \\
Internal friction angle $(\varphi)$ & degree & 32 \\
Elasticity module $(\mathrm{E})$ & $\mathrm{MPa}$ & 75.00 \\
Poisson ratio $(\mathrm{v})$ & - & 0.3 \\
Dry unit weight $(\gamma)$ & $\mathrm{kN} / \mathrm{m}^{3}$ & 18.4 \\
\hline
\end{tabular}

single tunnel diameter that was $9.17 \mathrm{~m}$, the dimension of the model has been chosen $30 \mathrm{~m}, 50 \mathrm{~m}$, and $75 \mathrm{~m}$ for wide, height, and length respectively. The boundaries of the model were considered free at the top and completely hinged constraint at the bottom, right and left of the model edges. In both single tunnel and twin tunnels, the simulation has been done for half-tunnel shape with the purpose of decreasing the processing time.

The "step by step" approach method consists of 5 steps has been selected for the machine movement. This approach has been used the first time by Dijk \& Kaalberg in 1998 for the shield tunneling model [52]. Each section has $1.5 \mathrm{~m}$ length and accordingly, the TBM moves ahead $1.5 \mathrm{~m}$ per step. Also, there is a $1.5 \mathrm{~m}$ gap (one step) between the end of the shield and lining segments location which has been considered for the grout injection. The tunnels axis has been placed on a depth of $25 \mathrm{~m}$ and the water level was considered $2 \mathrm{~m}$ below the ground surface. The cross-section of the tunnel is shown in Fig. 1. Although in some areas "very silty clayey sand" can be seen (green color), most of the route has a gravely sand environment and the tunnel alignment has been located in this part. Hence, with considering an small simplification, the gravely sand with silt was considered and the details of the soil are shown in Table 1.

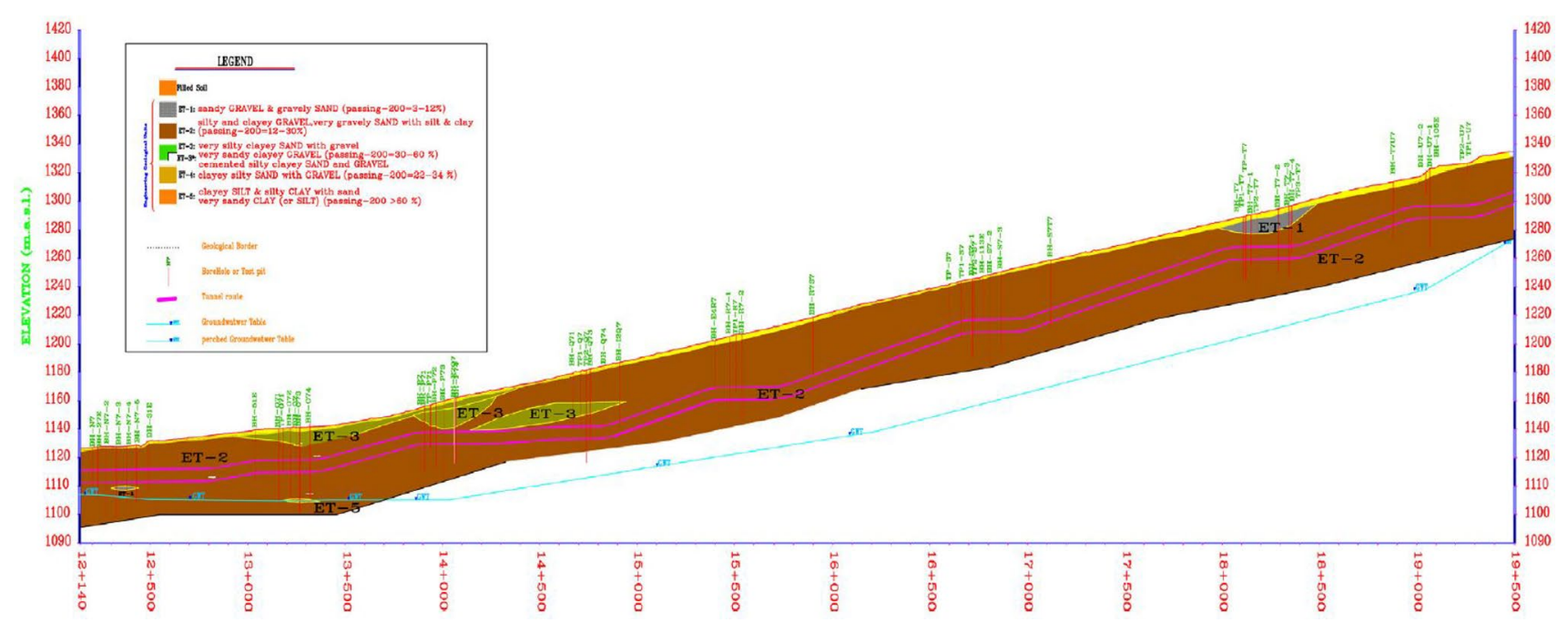

Fig. 1 The tunnel geology cross-section [44] 
The soil disturbance around the shield induced by cutter head activity, moving forward of the machine, and especially the conicity shape of the shield is one of the most critical parts of the tunnel modeling [6]. For this purpose, some ictitious displacement has been performed along with the shield to simulate of the ground subsidence induced by overcutting of the machine and the conicity shape of the shield. These displacement has been considered by contraction coefficient around the shield which are 0.1, 0.2, 0.3, 0.4, and 0.5. Furthermore, the shield strength and its thickness, machine weight, interaction between soil and shield, and final lining system have been considered in the modeling (Table 2, Table 3).

The same procedure consist of 5 steps has been assumed for the twin tunnels. On one hand, for avoiding any interaction between the tunnels, the horizontal clear distance between the tunnels was kept $20 \mathrm{~m}$ and on the other hand for noticing construction one of tunnels before the other, the left tunnel has considered $100 \mathrm{~m}$ ahead. In the EPB machines, the face supporting pressure must be as enough to withstand the soil weight [53]. Then the minimum value should be known in the first stage which is based on the active pressure coefficient of the soil (k) (Eq. 1).

$k=\frac{1-\sin \varphi}{1+\sin \varphi}$

In this study, the minimum value obtained by implementing $150 \mathrm{kPa}$ as the face pressure and decreasing gradually until the falling of the face. The achieved results for the facetop were $150 \mathrm{kPa}$ and $100 \mathrm{kPa}$ for single and twin tunnels respectively and this amount for the face-down were $200 \mathrm{kPa}$ in the single and $130 \mathrm{kPa}$ for the twin tunnels (Table 4).

\section{Results and Discussion}

According to the finite element simulation, the stress and displacement analysis of the tunnel's excavation were conducted. To measure the tunnel's interactions, it is necessary to understand the surface settlement and ground movements around the tunnels. Therefore, in this study, surface settlements are selected as the reference to investigate the reliability of the FEA results. The results have been explicated

Table 2 The specifications of simulated TBM shield

\begin{tabular}{lll}
\hline Parameters & Unit & Value \\
\hline Elasticity module in area (EA) & $\mathrm{MPa}$ & 8200 \\
Elasticity module in inertia (EI) & $\mathrm{kN} / \mathrm{m}^{2} / \mathrm{m}$ & 32 \\
Poisson ratio & - & 0.3 \\
Thickness & $\mathrm{cm}$ & 15.0 \\
\hline
\end{tabular}

Table 3 The specification of the final lining system

\begin{tabular}{lll}
\hline Parameters & Unit & Value \\
\hline Module of elasticity $\left(\mathrm{E}_{\text {ref }}\right)$ & $\mathrm{MPa}$ & 38,000 \\
Dry unit weight $(\gamma)$ & $\mathrm{kN} / \mathrm{m}^{3}$ & 25 \\
Poisson ratio $(v)$ & - & 0.2 \\
\hline
\end{tabular}

by focusing on the stresses and displacements around the tunnels and surface. The stress graphs and longitudinal displacements for the single tunnel and twin tunnels are shown in Figs. 2, 3 respectively.

Based on the longitudinal profile, the most settlement amount occurred at the end of the shield and just before grout injection in both single and twin tunnels. All settlement values were less than $2 \mathrm{~cm}$ in single tunnels and $1 \mathrm{~cm}$ in twin tunnels which had a good correlation with the field monitoring. The existence of stress and strain caused by environmental loads can lead to failure in different modes [54], however, the stresses around the tunnels becoming more uniform by passing forward of the tail.

The analysis was conducted on the influence of different parameters such as the face supporting pressure, grout injection pressure, soil cohesive as well as the clear distance of the twin tunnels. At the first stage and for the single tunnel, the supporting face pressure increased from 130 to $190 \mathrm{kPa}$ in the three steps by the rate of $20 \mathrm{kPa}$ per step (Figs. 4, 5).

Increasing the pressure from 130 to $150 \mathrm{kPa}$ led to a $1 \mathrm{~mm}$ reduction in the settlements. However, this reduction rate stopped at the cumulative settlement of $1.5 \mathrm{~mm}$. It shows the limit effect of the face pressure on the ground movements. Moreover, the place of the maximum settlement moves toward the tail by implementing higher amounts of face pressure. This can be associated with the stability area generated by the high pressure of the face which continues to the tail.

The same analysis has been performed for the twin tunnels. Since the default face pressure of the twin tunnels was $100 \mathrm{kPa}$, then the pressure increased to $160 \mathrm{kPa}$ in the 3 steps (Fig. 6). The results showed a $1 \mathrm{~mm}$ decrease in the surface settlement for changing the pressure from 100

Table 4 The EPB pressure parameters specifications

\begin{tabular}{lll}
\hline Item & Single tunnel & Twin tunnel \\
\hline Face pressure $(\mathrm{kPa})$ & $\begin{array}{l}150 \text { at the top-face } \\
200 \text { at the down-face }\end{array}$ & 100 at the top \\
& 100 & 70 \\
& 2100 & 730 \\
Grout pressure $(\mathrm{kPa})$ & & 100 \\
Hydraulic jacks pressure & $(\mathrm{kPa})$ & $20,25,30$ \\
Longitudinal distance $(\mathrm{m})$ & - & \\
Clear distance $(\mathrm{m})$ & - &
\end{tabular}




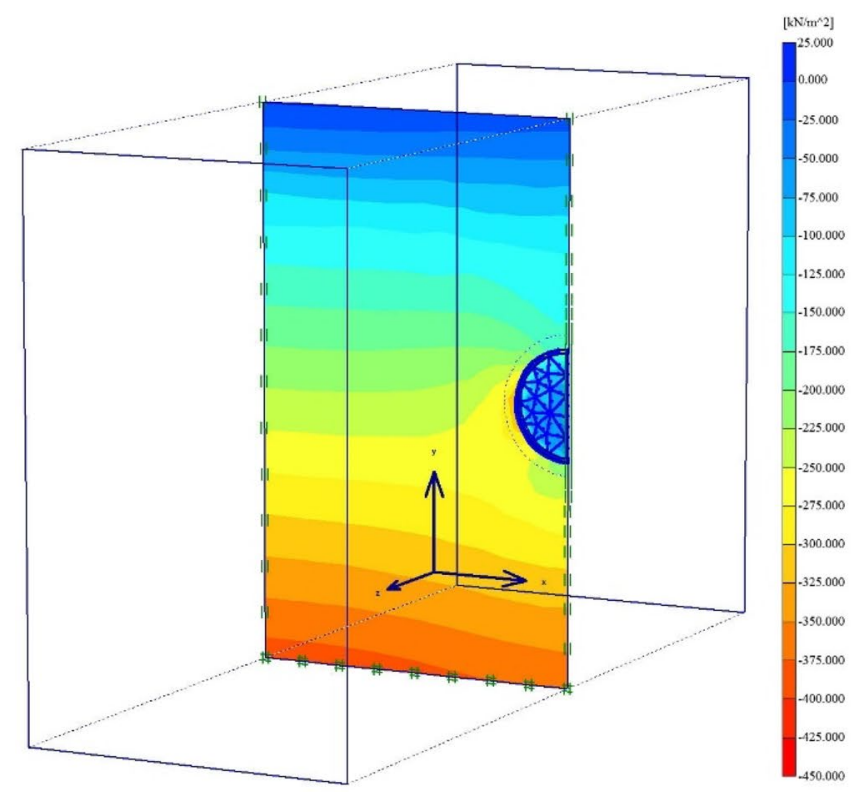

(a)

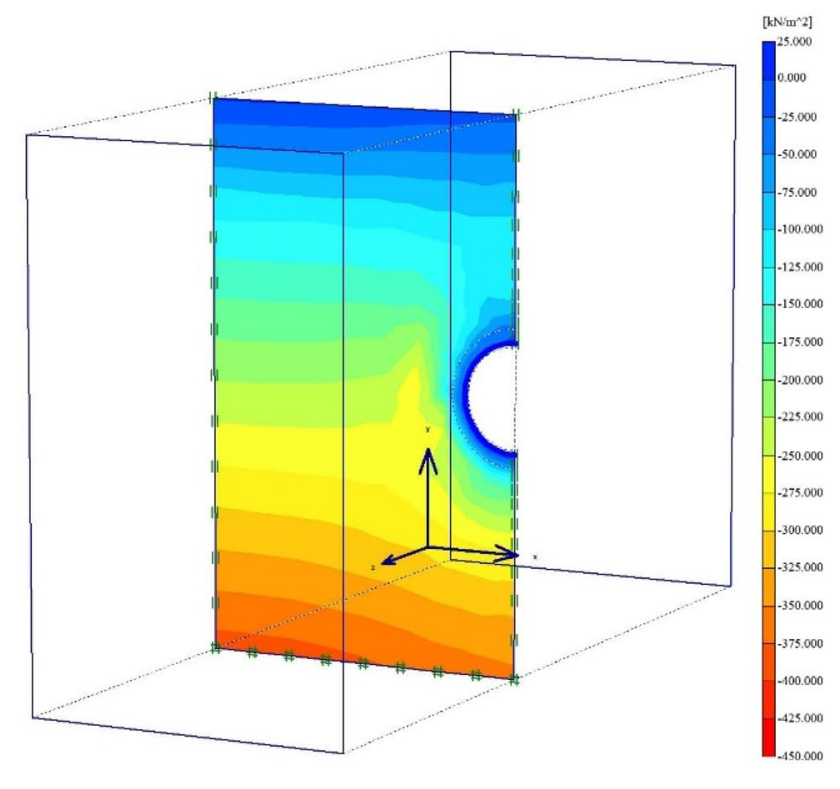

(b)

Fig. 2 The stress results caused by excavation $\mathbf{a}$ At the face and $\mathbf{b}$ At the end of tail

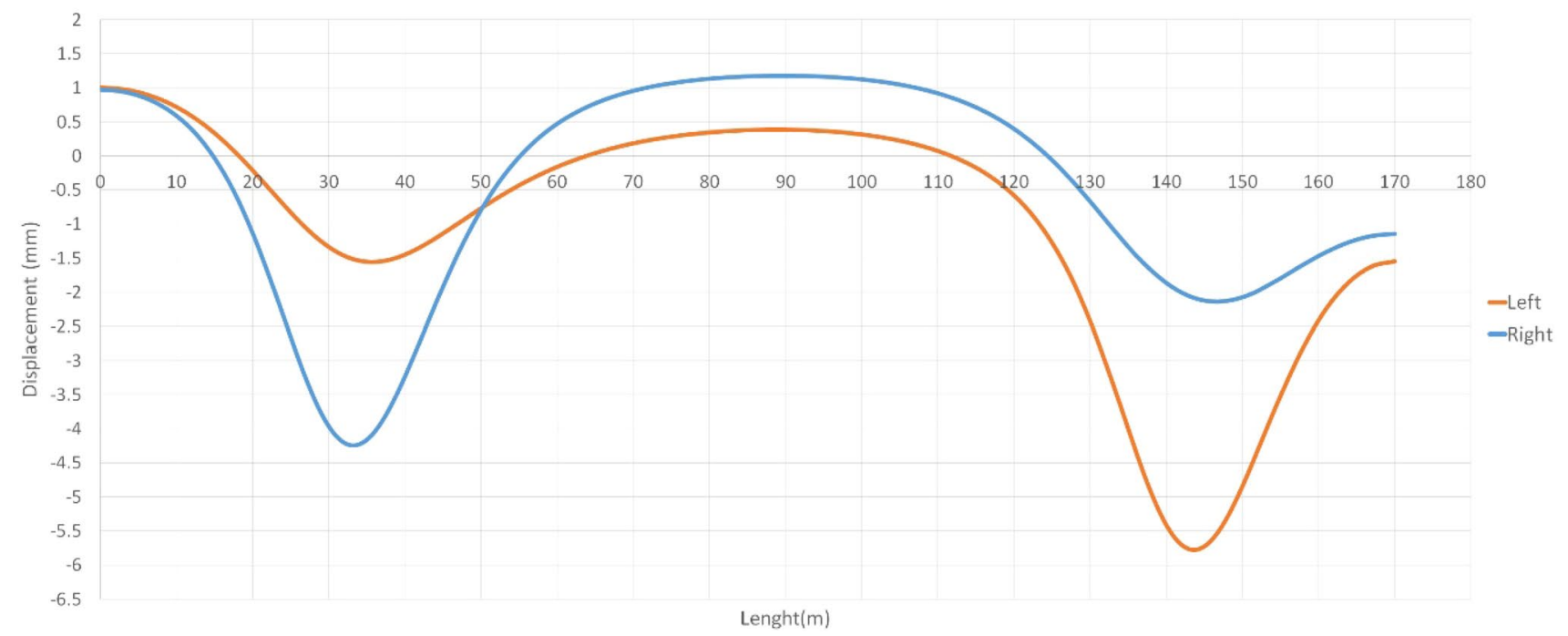

Fig. 3 Longitudinal settlement profile for the twin tunnels

to $120 \mathrm{kPa}$. But for other pressures, neither surface settlement nor the place of maximum settlement changed. Thus, increasing the face pressure in the field up to $120 \mathrm{kPa}$ can decrease the settlements and for more pressures, it has no effect on the ground movements. The maximum value of the settlement on the right tunnel was $1 \mathrm{~mm}$ less than the left one which was $100 \mathrm{~m}$ ahead (Fig. 7).

In addition, the transverse influenced domain has been investigated (Fig. 8). As can be seen, the ground settlements did not become zero after $20 \mathrm{~m}$ lengths of the tunnel axis.
It means that in this case, these two tunnels may have some interaction with each other. For this purpose, the analysis of the clear distance effect has been performed to clarify the impact of the distance between the tunnels.

New tunnel construction in proximity to existing ones, which happens in twin tunnels, has a considerable negative effect on the existing tunnel $[55,56]$. Therefore the clear distance between the tunnels was investigated for three different lengths of $20 \mathrm{~m}, 25 \mathrm{~m}$, and $30 \mathrm{~m}$. According to the finite element model, examining the other distances was 


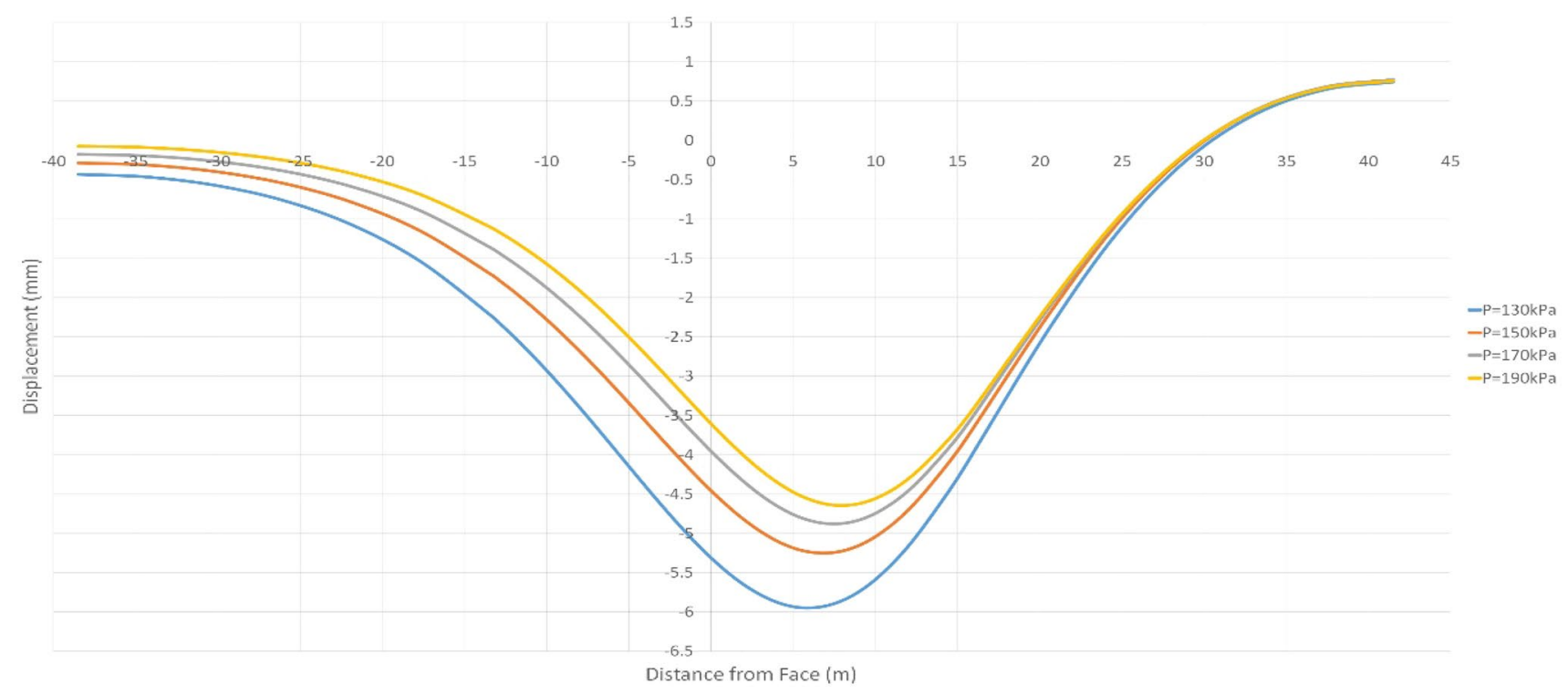

Fig. 4 Effect of the supporting face pressure on the longitudinal settlement profile of single tunnel

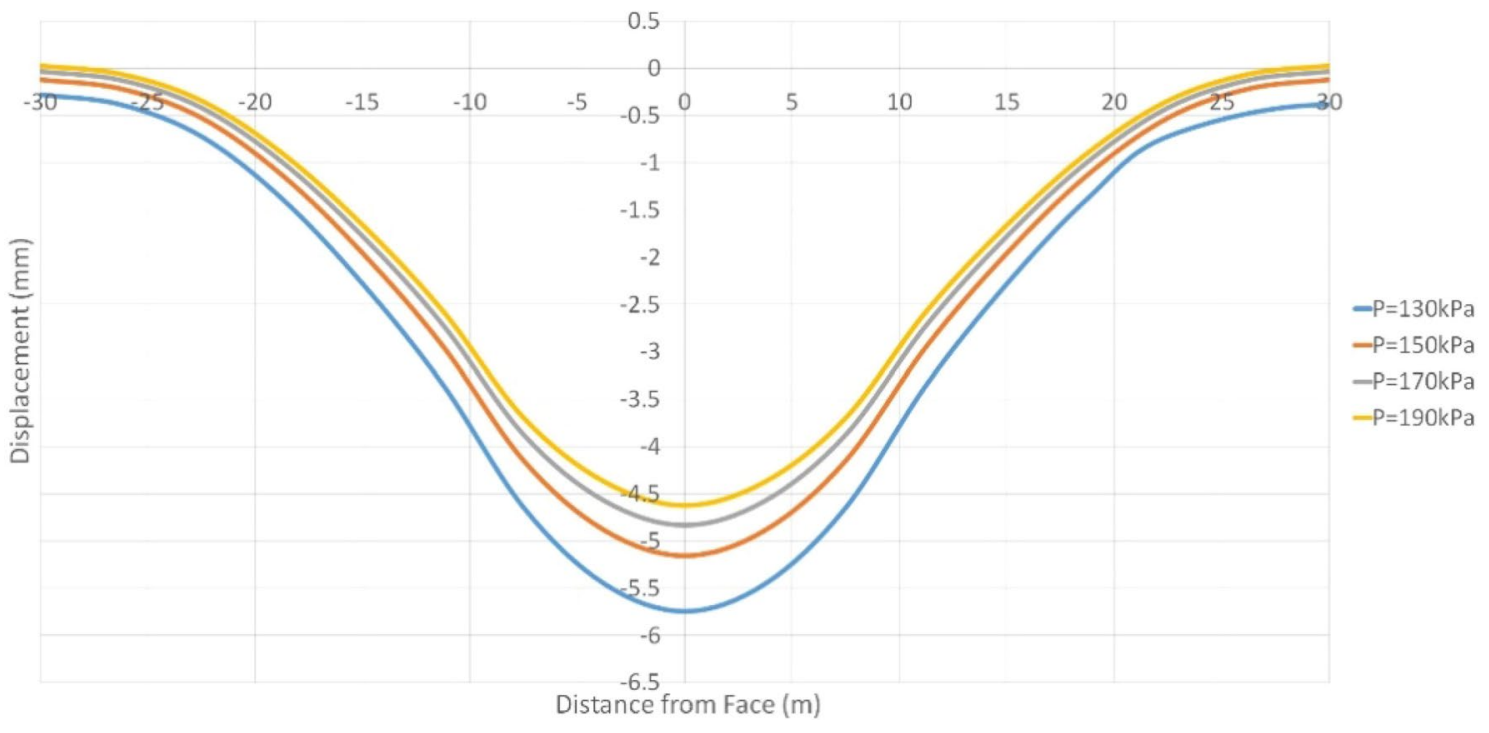

Fig. 5 Effect of the supporting face pressure on the transverse settlement profile of single tunnel

difficult because of the huge amount of the elements and long run-time. The results showed that the tunnels have some interaction with each other on distances of $20 \mathrm{~m}$ and less. (Figs. 9, 10).

As expected, the distance analysis showed that for more distances between two tunnels, the settlements at the top spot decreasing. It can be related to eliminating soil disturbance around the tunnel which has created by the excavation of another tunnel. For the distances of $20 \mathrm{~m}$ and $25 \mathrm{~m}$, the settlements were affected on the lengths of $+110 \mathrm{~m}$ and $-110 \mathrm{~m}$ for the left tunnel and right tunnel respectively. Nevertheless, this effect has disappeared for the distance of $30 \mathrm{~m}$ and the diagram has a smooth slope at this point. Therefore the distance of $30 \mathrm{~m}$ can be present as the minimum clear distance for avoiding any interaction between the tunnels. Indeed for the more distances, the tunnels should be analyzed separately and as two single tunnels. Similarly in the transverse profile graph (Fig. 11), the settlements in the affected area of the tunnels were zero at this distance. Although for more distances the transverse settlements decreased, still there are some ground movements for the distances of $20 \mathrm{~m}$ and 25 that are $1 \mathrm{~mm}$ and $0.5 \mathrm{~mm}$. 


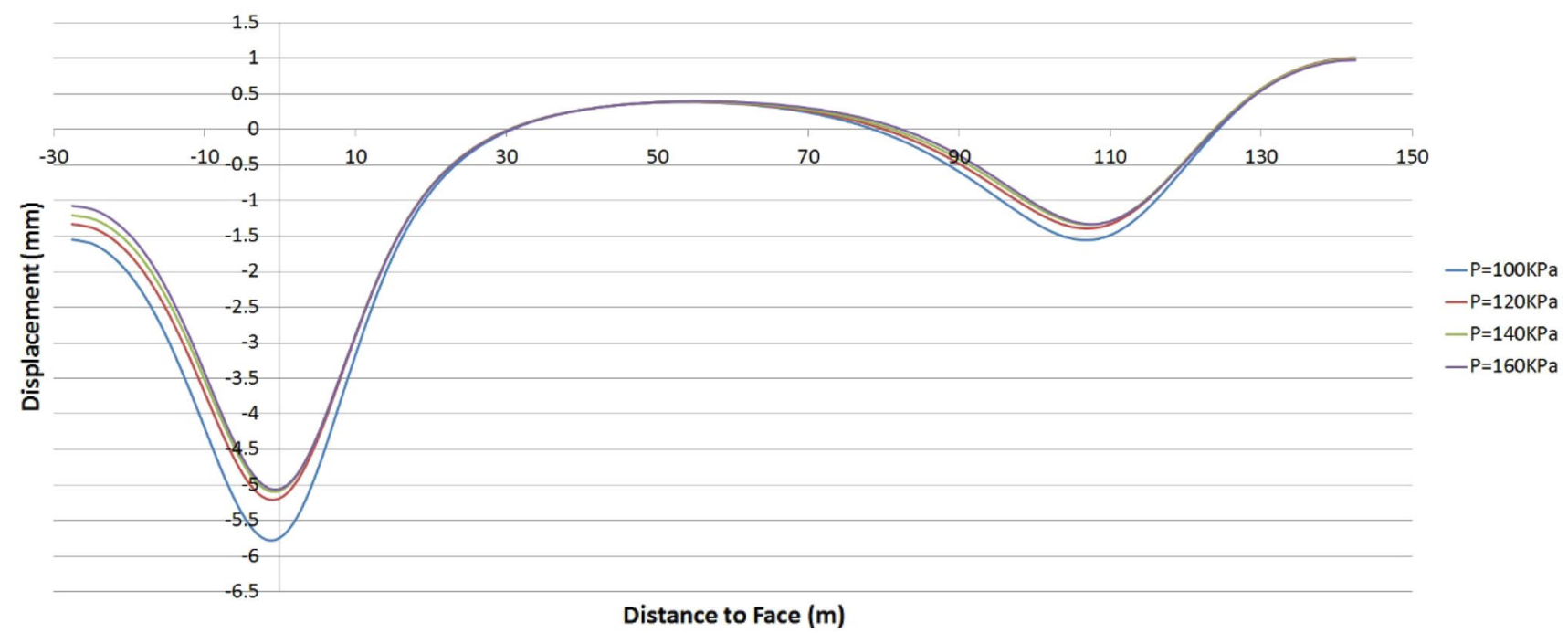

Fig. 6 Effect of the supporting face pressure on the longitudinal settlement profile of left tunnel

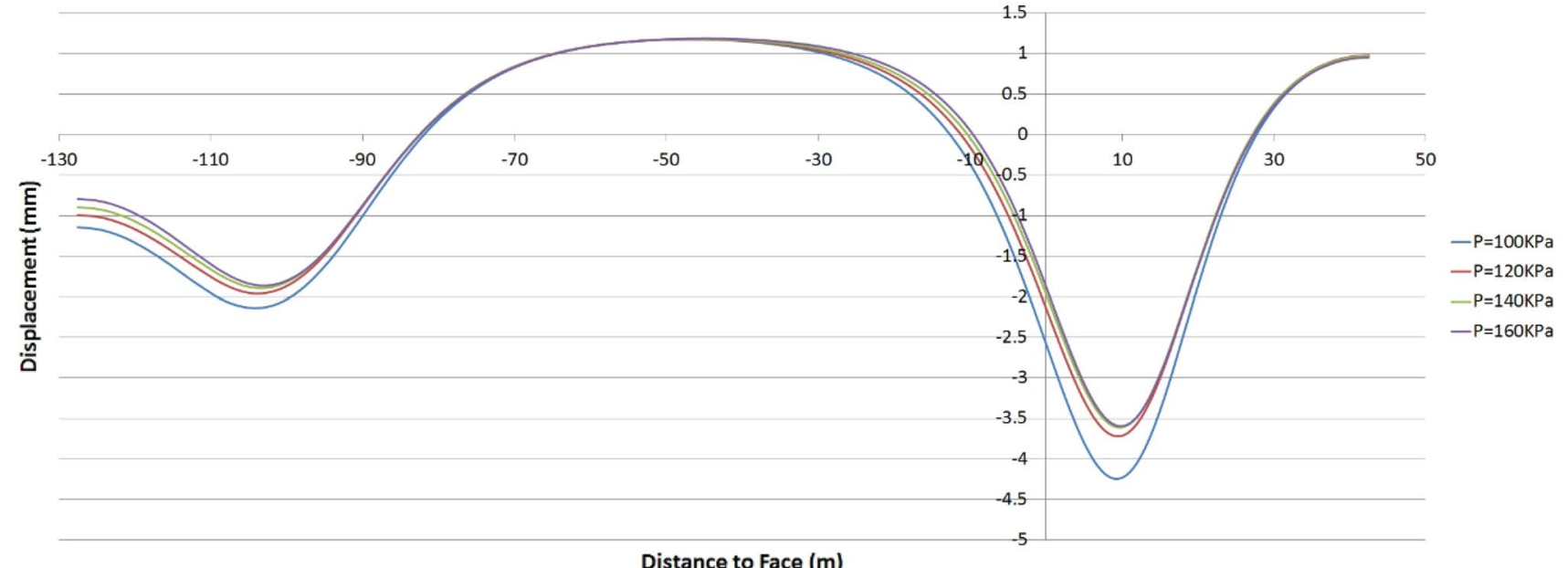

Fig. 7 Effect of the supporting face pressure on the longitudinal settlement profile of right tunnel

At the end of the tail and just after that, there is $1.5 \mathrm{~m}$ space between the shield and the lining segments and this is the place that grout injection is applied. The grout injection simulated as the circumferences force with the first pressure of $130 \mathrm{kPa}$ for the single tunnel and $70 \mathrm{kPa}$ for twin tunnels. (Fig. 12). The results of the grout pressure effect on the surface movements had shown in Figs. 13, 14 for a single tunnel in longitudinal and transverse profile respectively. The same results for the twin tunnels had shown in Figs. 15, 16, 17.

As can be seen, the grout pressure has a few influences on the long-distance settlements and the near zones are more subjecting to the change. The rate of decrease is more constant in the transverse graphs. However, the total amount of recovery is less than $1 \mathrm{~mm}$ for increasing the pressure from 130 to $250 \mathrm{kPa}$ and $70 \mathrm{kPa}$ to $160 \mathrm{kPa}$ for single and twin tunnels respectively. Therefore it implies that the pressure of grout is not an effective parameter for surface settlements. The main responsibility of the grout is providing stable zones around the excavation area for avoiding the later pressure on the linings from outside.

\section{Conclusions}

In this study, a complete three-dimensional finite element modeling of the single and twin tunnels of the metro has been employed. The study performed an investigation on the influence of the effective parameters of the EPB-TBM 


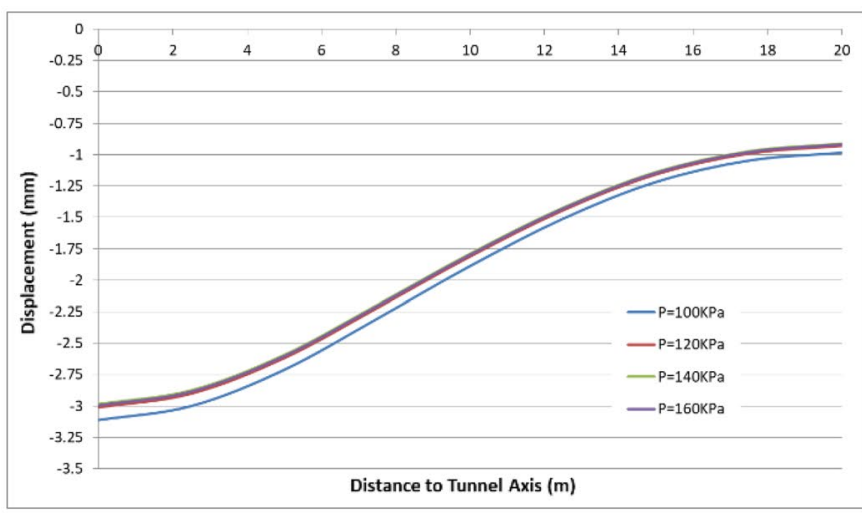

(a)

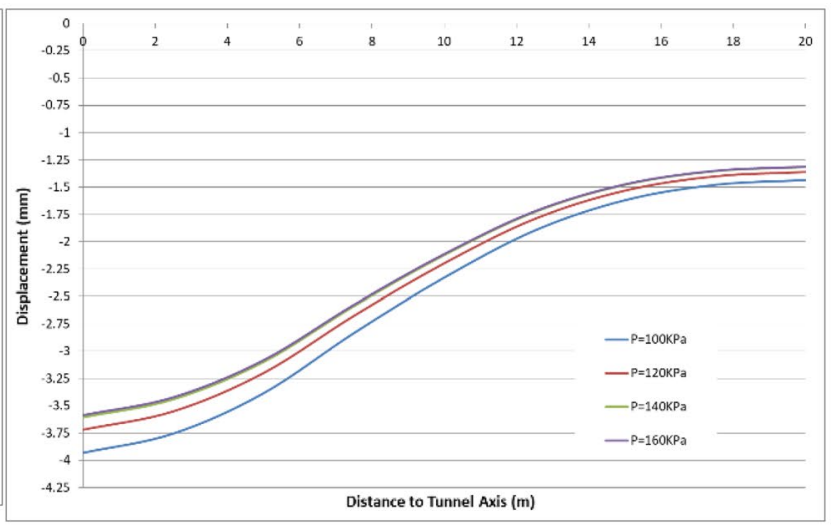

(b)

Fig. 8 Effect of the supporting face pressure on the transverse settlement profile $\mathbf{a}$ left tunnel and $\mathbf{b}$ right tunnel

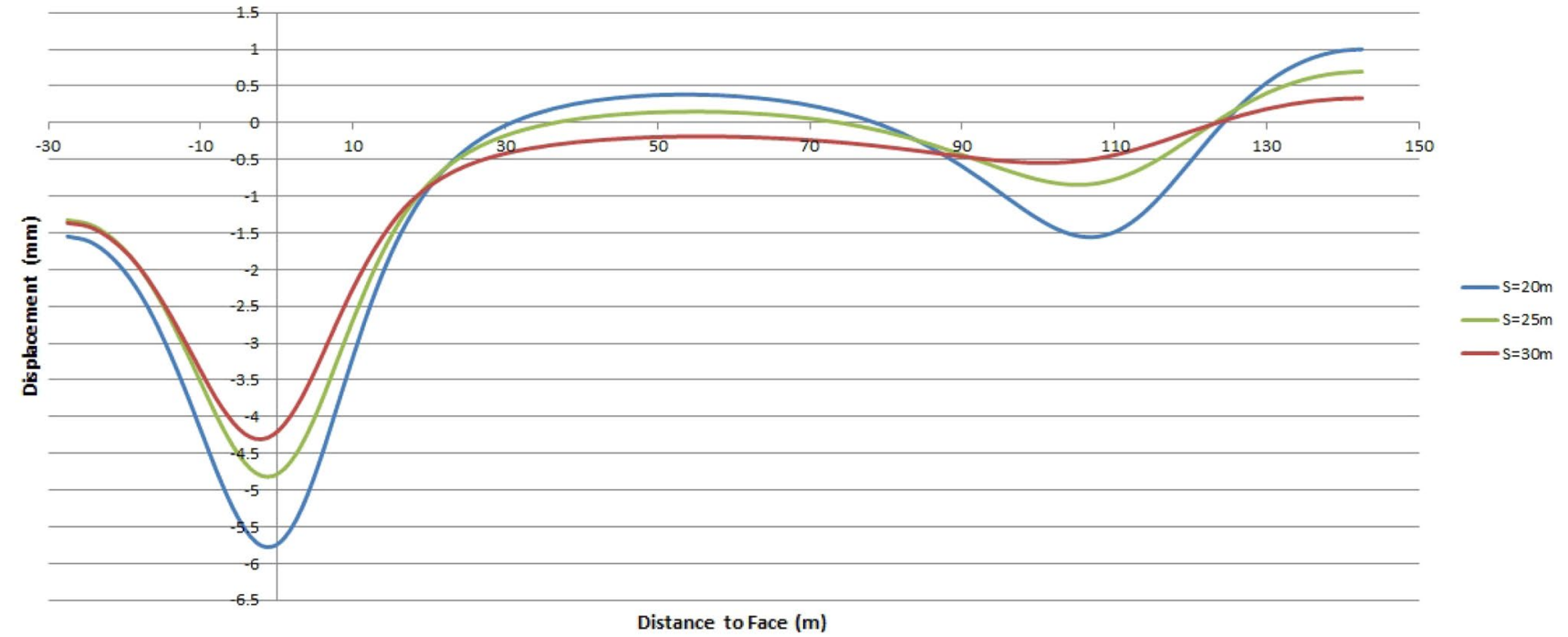

Fig. 9 Effect of the clear distance between the tunnels for the left tunnel

through excavation. Face supporting pressure, tail grout injection, overcutting of the cutter head, shield conicity, as well as the final lining system considered in the model. Also, effects of the face pressure, grout injection pressure, and clear distance of twin tunnels investigated. Based on the numerical analysis results, the achieved settlements were valid and standard in comparison to the other studies and based on the local report. The finite element analysis showed the maximum settlement of $6 \mathrm{~mm}$ in the single tunnel and for the twin tunnels, the maximum surface settlement was $5.7 \mathrm{~mm}$ and $4.2 \mathrm{~mm}$ for the left tunnel and right tunnel respectively. Moreover, the following results have been drawn from the 3D numerical analysis:
1. The maximum settlement induced by the machine excavation occurred in the end tail of the shield which is the place of grouting. In the twin tunnels, the achieved settlement from the first tunnel excavation is close to the single tunnel settlement. But for the second tunnel, the settlements are less. It seems to be the effect of soil disturbance created by the first tunnel excavation or existing final lining system.

2. The face supporting pressure has more effects on the settlements than grout injection. Also, this amount was higher in the single tunnel than the twin tunnels. The surface movements improved $1.5 \mathrm{~mm}$ in the single tunnels by $60 \mathrm{kPa}$ increasing of the face pressure. But in the 


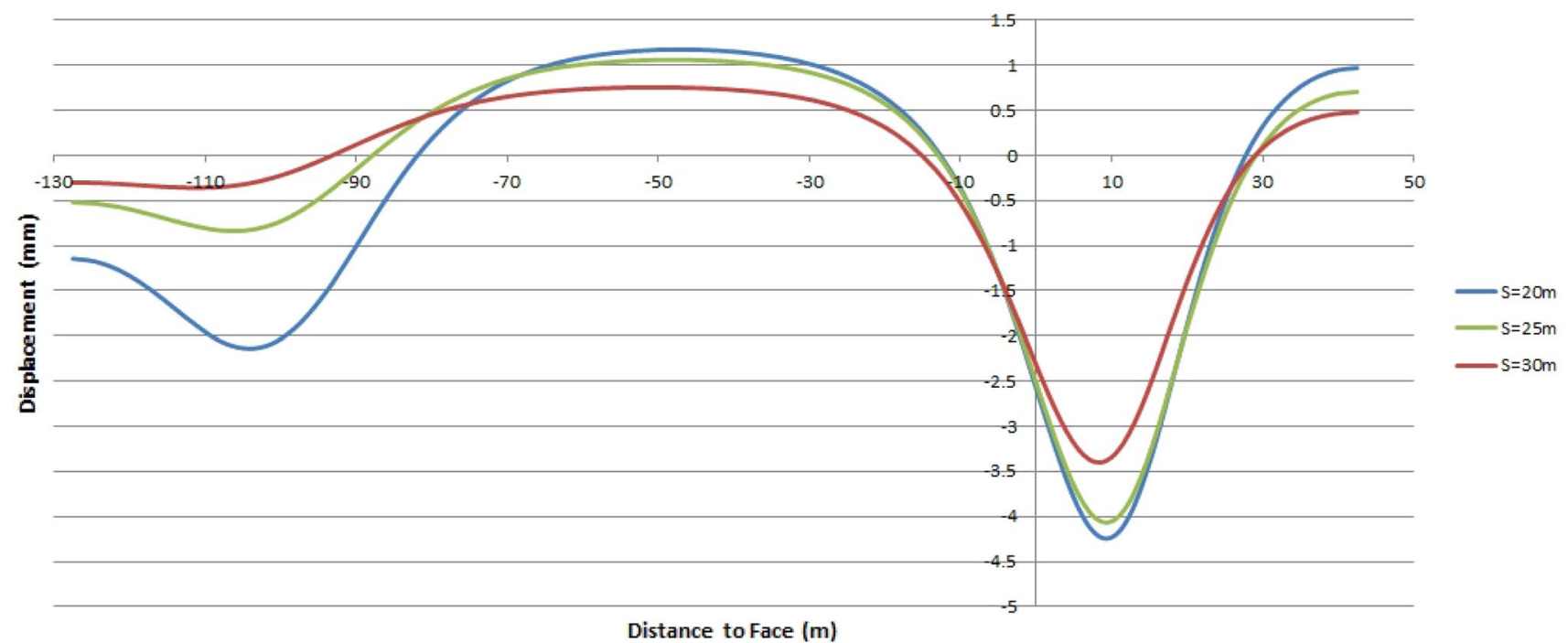

Fig. 10 Effect of the clear distance between the tunnels for the right tunnel

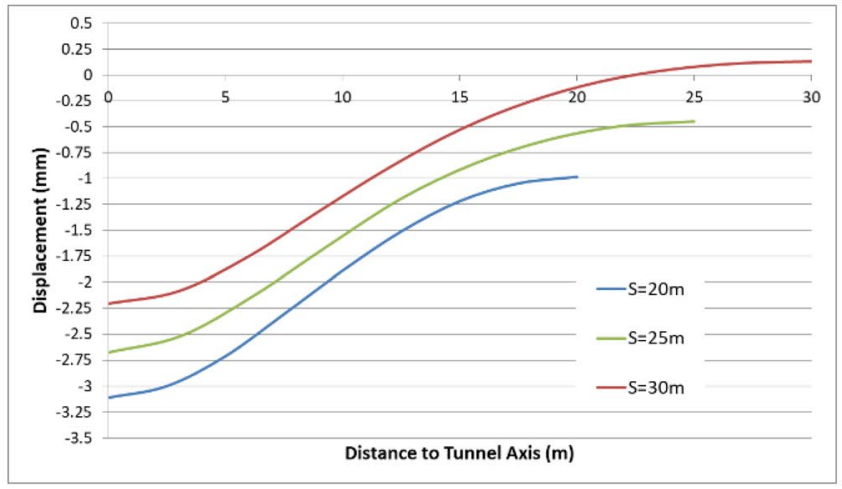

(a)

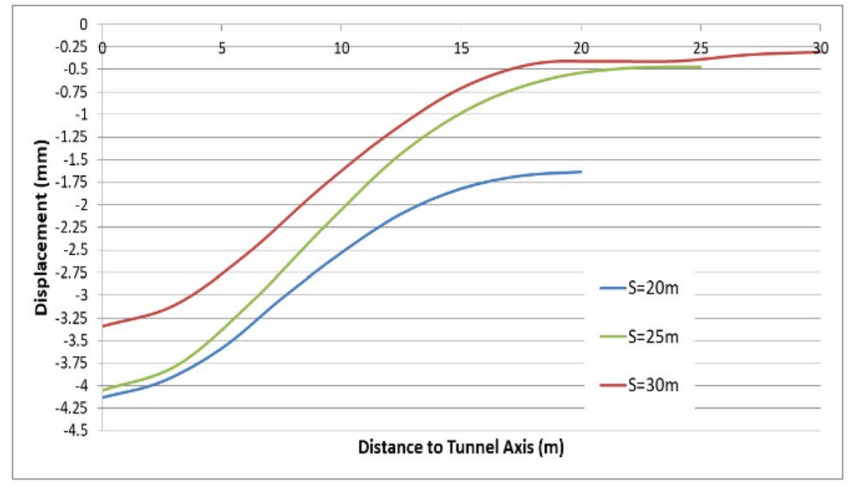

(b)

Fig. 11 Effect of the clear distance between the tunnels on the transverse settlement profile a left tunnel and $\mathbf{b}$ right tunnel

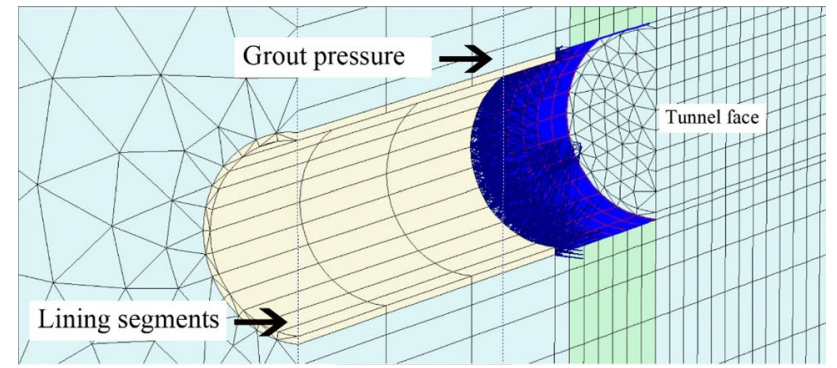

Fig. 12 The applied grout injection pressure as the circumference force in the $1.5 \mathrm{~m}$ gap twin tunnels, the most surface settlement improvement obtained around $0.5 \mathrm{~mm}$.

3. Influence of the grout injection pressure on the surface settlements is insignificant. The best settlements improvement reported as $1 \mathrm{~mm}$ by $120 \mathrm{kPa}$ increasing of the injection pressure in the twin tunnels. However, the grout pressure has more influence on the twin tunnels. It can be associated with the smaller radius of the tunnels.

4. The influence of the clear distance of the tunnels decreased to zero after $S=30 \mathrm{~m}$. As a result, this space can be reported as the maximum clear distance between the tunnels for considering them as twin tunnels. For 


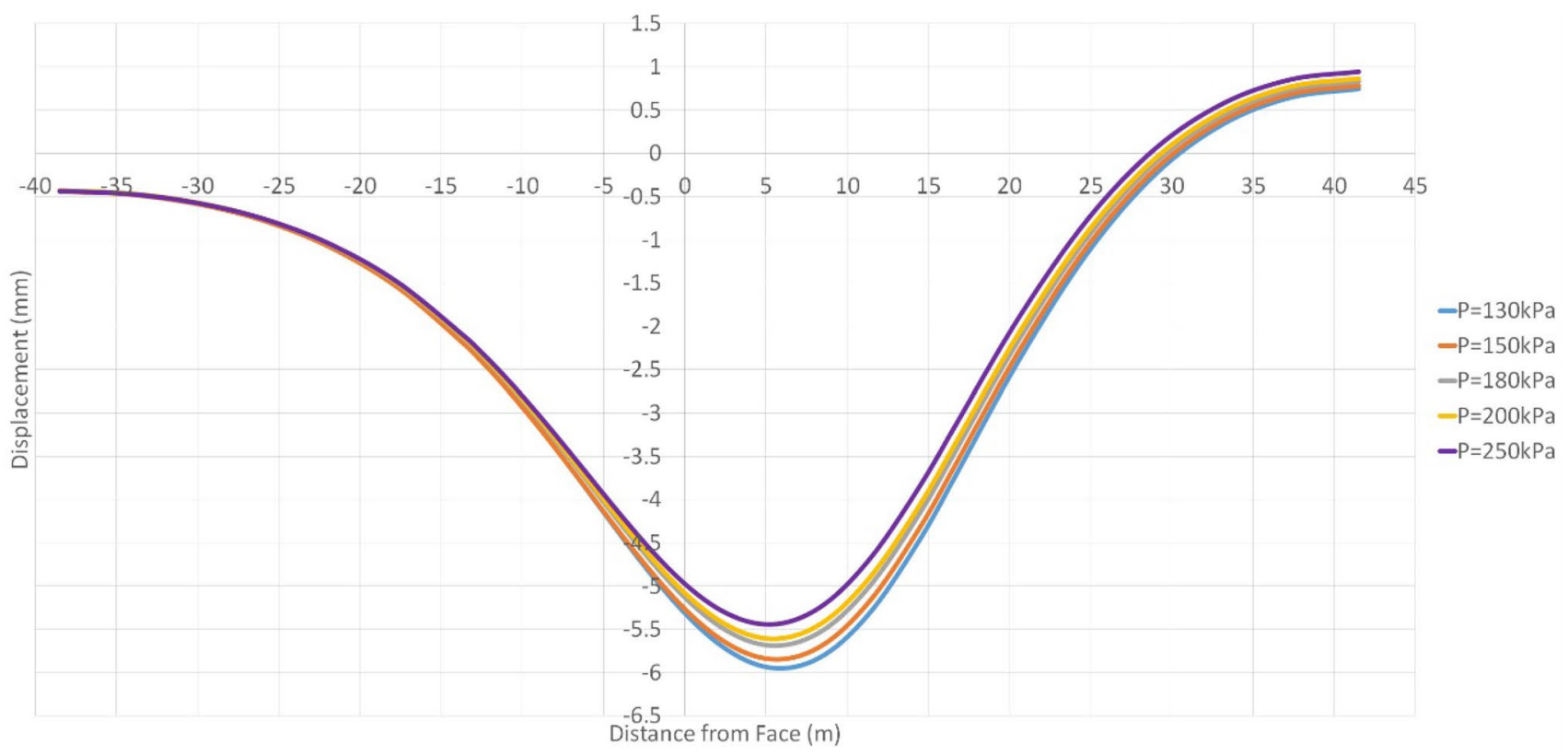

Fig. 13 The effect of grout injection on the longitudinal settlement profile

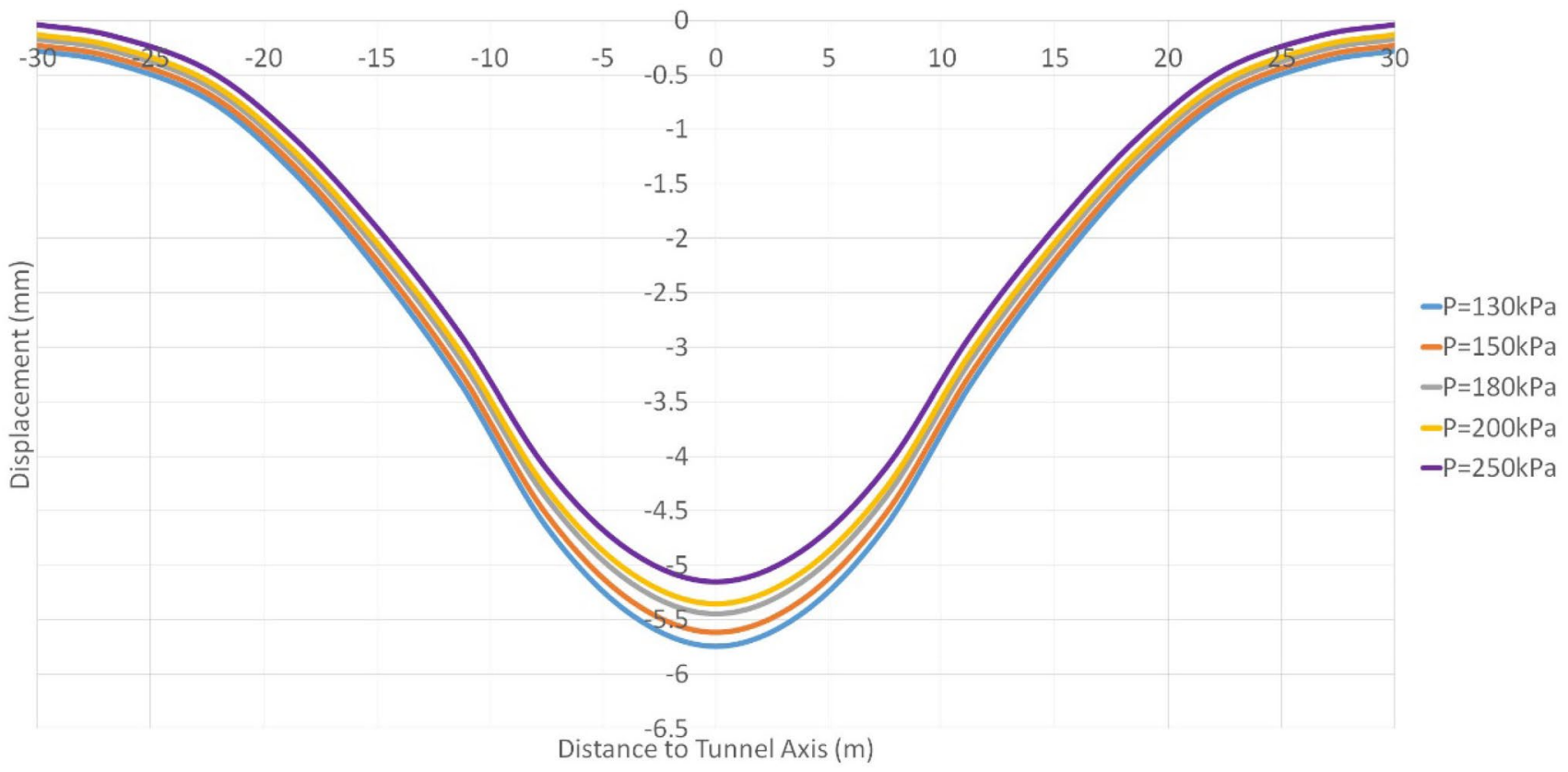

Fig. 14 The effect of grout injection on the transverse settlement profile 


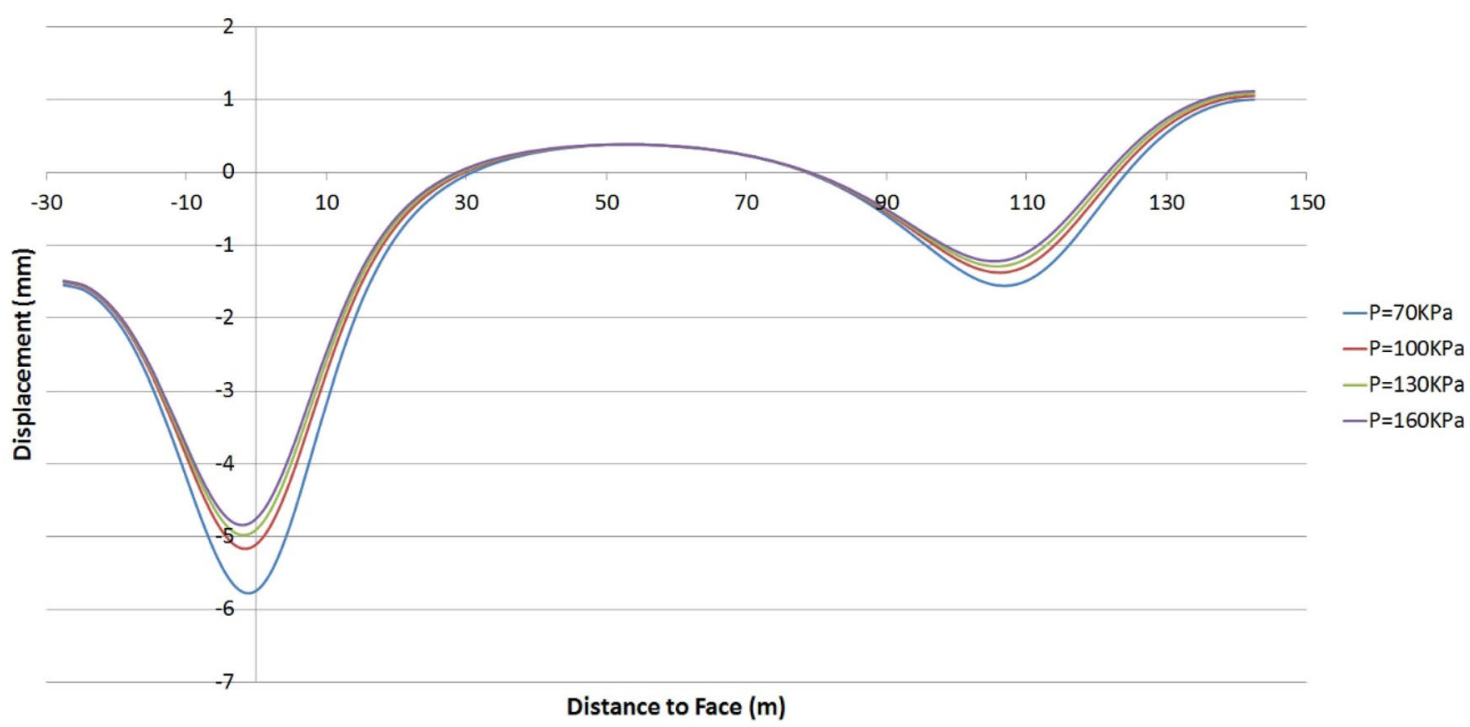

Fig. 15 The effect of grout injection on the longitudinal profile for the left tunnel

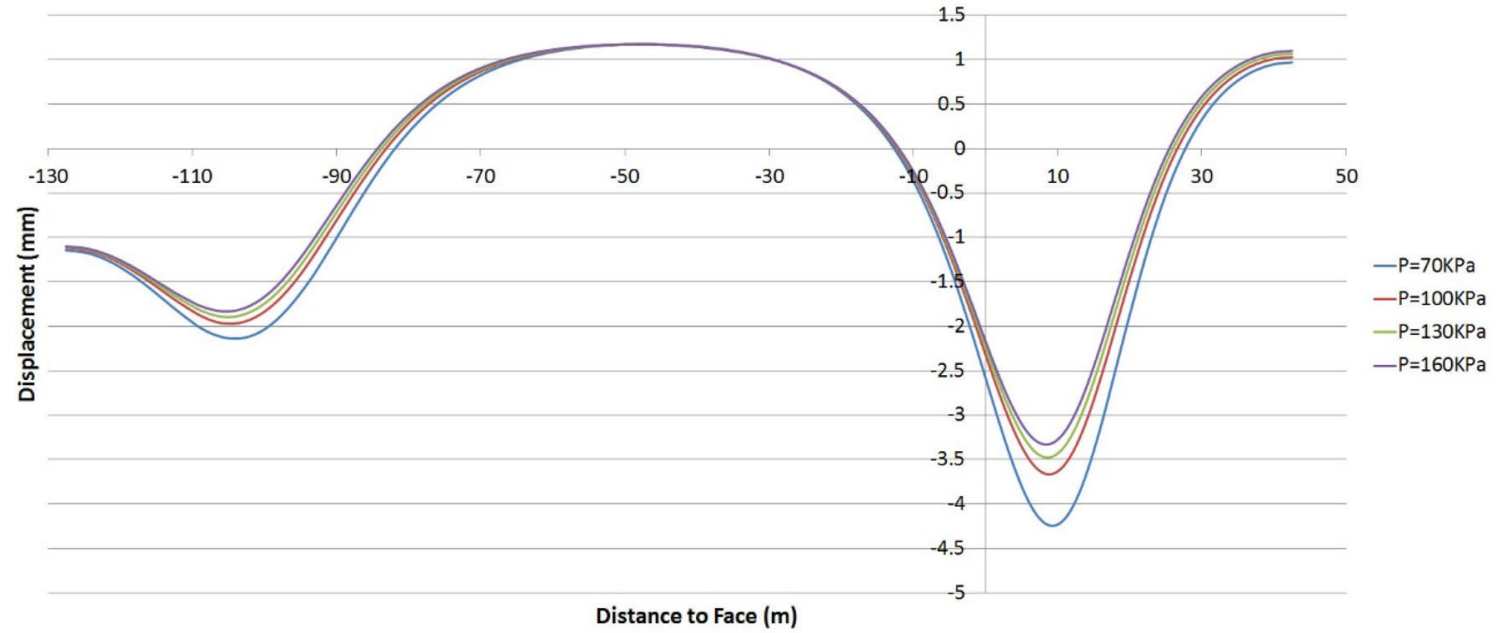

Fig. 16 The effect of grout injection on the longitudinal profile for the right tunnel

more distances, the tunnels should be analyzed separately and as two different single tunnels.

By increasing the face supporting pressure in the single tunnels, the place of maximum settlement moved to the backward. The analysis showed that increasing the pressure from 130 to $190 \mathrm{kPa}$ caused moving the maximum settlement place $2 \mathrm{~m}$ up to $3 \mathrm{~m}$ backward. However, for the twin tunnels, no moving happened and it may be related to the smaller diameter or less applied face pressure. 


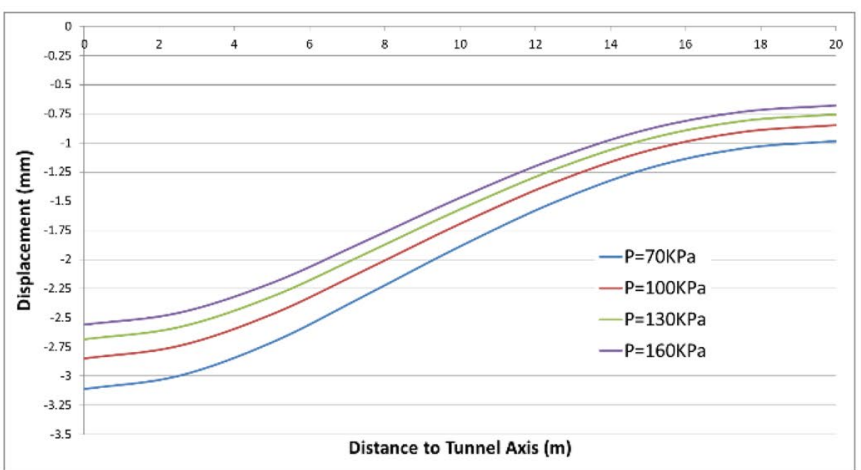

(a)

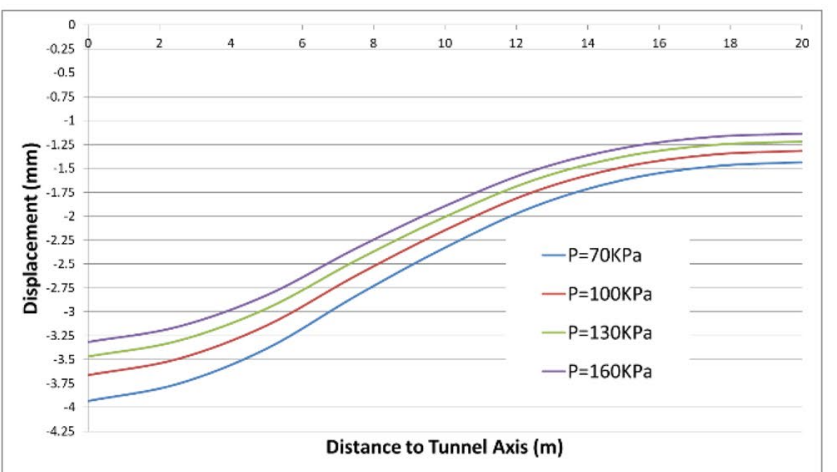

(b)

Fig. 17 Effect of grout injection pressure on the transverse settlement profile $\mathbf{a}$ left tunnel and $\mathbf{b}$ right tunnel

Funding Open access funding provided by the Qatar National Library.

Open Access This article is licensed under a Creative Commons Attribution 4.0 International License, which permits use, sharing, adaptation, distribution and reproduction in any medium or format, as long as you give appropriate credit to the original author(s) and the source, provide a link to the Creative Commons licence, and indicate if changes were made. The images or other third party material in this article are included in the article's Creative Commons licence, unless indicated otherwise in a credit line to the material. If material is not included in the article's Creative Commons licence and your intended use is not permitted by statutory regulation or exceeds the permitted use, you will need to obtain permission directly from the copyright holder. To view a copy of this licence, visit http://creativecommons.org/licenses/by/4.0/.

\section{References}

1. Avunduk, E., \& Copur, H. (2018). Empirical modeling for predicting excavation performance of EPB TBM based on soil properties. Tunnelling and Underground Space Technology, 71, 340-353

2. Zhou, C., et al. (2018). Data based complex network modeling and analysis of shield tunneling performance in metro construction. Advanced Engineering Informatics, 38, 168-186

3. Dalgıç, S. (2003). Tunneling in fault zones, Tuzla tunnel, Turkey. Tunnelling and Underground Space Technology, 18(5), 453-465

4. Namli, M., \& Bilgin, N. (2017). A model to predict daily advance rates of EPB-TBMs in a complex geology in Istanbul. Tunnelling and Underground Space Technology, 62, 43-52

5. Zheng, G., et al. (2019). Volumetric behaviour of subsurface ground due to tunnelling in completely drained granular soil. Computers and Geotechnics, 116, 103217

6. Zhang, Z. X., et al. (2016). Three-dimensional finite-element analysis on ground responses during twin-tunnel construction using the URUP method. Tunnelling and Underground Space Technology, 58, 133-146

7. Liang, R., et al. (2016). Effects of above-crossing tunnelling on the existing shield tunnels. Tunnelling and Underground Space Technology, 58, 159-176

8. Novozhenin, S. U., \& Vystrchil, M. G. (2016). New method of surface settlement prediction for saint-petersburg metro escalator tunnels excavated by EPB TBM. Procedia Engineering, 150, 2266-2271
9. Culí, L., et al. (2016). Modelling of the EPB TBM shield tunnelling advance as a tool for geological characterization. Tunnelling and Underground Space Technology, 56, 12-21

10. Jin, D., et al. (2018). Analysis of the settlement of an existing tunnel induced by shield tunneling underneath. Tunnelling and Underground Space Technology, 81, 209-220

11. Hulme, T. W., \& Burchell, A. J. (1999). Tunnelling projects in Singapore: an overview. Tunnelling and Underground Space Technology, 14(4), 409-418

12. Carrieri, G., et al. (2006). Torino metro line 1: Use of three TBMEPBs in very coarse grained soil conditions. Tunnelling and Underground Space Technology, 21(3), 274-275

13. Huang, X., et al. (2018). Application and prospect of hard rock TBM for deep roadway construction in coal mines. Tunnelling and Underground Space Technology, 73, 105-126

14. Zhang, Z., \& Huang, M. (2014). Geotechnical influence on existing subway tunnels induced by multiline tunneling in Shanghai soft soil. Computers and Geotechnics, 56, 121-132

15. Abd-El Rahim, H. H. A., et al. (2015). Twin tunnel configuration for Greater Cairo metro line No. 4. Computers and Geotechnics, 68, 66-77

16. Ağbay, E., \& Topal, T. (2020). Evaluation of twin tunnel-induced surface ground deformation by empirical and numerical analyses (NATM part of Eurasia tunnel, Turkey). Computers and Geotechnics, 119, 103367

17. Mirhabibi, A., \& Soroush, A. (2012). Effects of surface buildings on twin tunnelling-induced ground settlements. Tunnelling and Underground Space Technology, 29, 40-51

18. Forsat, M., Mirjavadi, S. S., \& Hamouda, A. M. S. (2019). Investigation of the effect of larestan's pipeline water on the mechanical properties of concretes containing granite aggregates. Advances in Civil Engineering, 2019, 11

19. Chen, R., et al. (2016). Investigation of response of metro tunnels due to adjacent large excavation and protective measures in soft soils. Tunnelling and Underground Space Technology, 58, 224-235

20. Cheng, W.-C., et al. (2018). Shield tunnel uplift and deformation characterisation: A case study from Zhengzhou metro. Tunnelling and Underground Space Technology, 79, 83-95

21. Vinod, M., \& Khabbaz, H. (2019). Comparison of rectangular and circular bored twin tunnels in weak ground. Underground Space, 4(4), 328-39

22. Liu, Q., \& Wang, R. (2012). Dynamic response of twin closelyspaced circular tunnels to harmonic plane waves in a full space. Tunnelling and Underground Space Technology, 32, 212-220 
23. Mroueh, H., \& Shahrour, I. (2008). A simplified 3D model for tunnel construction using tunnel boring machines. Tunnelling and Underground Space Technology, 23(1), 38-45

24. Chu, B.-L., et al. (2007). Mechanical behavior of a twin-tunnel in multi-layered formations. Tunnelling and Underground Space Technology, 22(3), 351-362

25. Do, N.-A., et al. (2014). Three-dimensional numerical simulation of a mechanized twin tunnels in soft ground. Tunnelling and Underground Space Technology, 42, 40-51

26. Choi, J.-I., \& Lee, S.-W. (2010). Influence of existing tunnel on mechanical behavior of new tunnel. KSCE Journal of Civil Engineering, 14(5), 773-783

27. Suwansawat, S., \& Einstein Herbert, H. (2007). Describing settlement troughs over twin tunnels using a superposition technique. Journal of Geotechnical and Geoenvironmental Engineering, 133(4), 445-468

28. Fang, Q., et al. (2016). Ground surface settlements due to construction of closely-spaced twin tunnels with different geometric arrangements. Tunnelling and Underground Space Technology, $51,144-151$

29. Chen, F.-Q., Lin, L.-B., \& Li, D.-Y. (2019). Analytic solutions for twin tunneling at great depth considering liner installation and mutual interaction between geomaterial and liners. Applied Mathematical Modelling, 73, 412-441

30. Do, N.-A., Dias, D., \& Oreste, P. (2016). 3D numerical investigation of mechanized twin tunnels in soft ground-Influence of lagging distance between two tunnel faces. Engineering Structures, 109, 117-125

31. Afifipour, M., et al. (2011). Interaction of twin tunnels and shallow foundation at Zand underpass, Shiraz metro Iran. Tunnelling and Underground Space Technology, 26(2), 356-363

32. Fargnoli, V., Boldini, D., \& Amorosi, A. (2015). Twin tunnel excavation in coarse grained soils: Observations and numerical back-predictions under free field conditions and in presence of a surface structure. Tunnelling and Underground Space Technology, 49, 454-469

33. Han, M. D., et al. (2017). Dynamic numerical simulation of cutterhead loads in TBM tunnelling. Tunnelling and Underground Space Technology, 70, 286-298

34. Wang, F., et al. (2019). Thermal analysis and air temperature prediction in TBM construction tunnels. Applied Thermal Engineering, 158, 113822

35. Hasanpour, R., et al. (2018). Parametric study of the impacts of various geological and machine parameters on thrust force requirements for operating a single shield TBM in squeezing ground. Tunnelling and Underground Space Technology, 73, 252-260

36. Lambrughi, A., Medina Rodríguez, L., \& Castellanza, R. (2012). Development and validation of a 3D numerical model for TBMEPB mechanised excavations. Computers and Geotechnics, 40, 97-113

37. Chapman, D. N., et al. (2006). The use of model tests to investigate the ground displacements associated with multiple tunnel construction in soil. Tunnelling and Underground Space Technology, 2l(3), 413

38. Farrokh, E., Mortazavi, A., \& Shamsi, G. (2006). Evaluation of ground convergence and squeezing potential in the TBM driven Ghomroud tunnel project. Tunnelling and Underground Space Technology, 21(5), 504-510

39. Neaupane, K. M., \& Adhikari, N. R. (2006). Prediction of tunneling-induced ground movement with the multi-layer perceptron. Tunnelling and Underground Space Technology, 21(2), 151-159
40. Klar, A., Dromy, I., \& Linker, R. (2014). Monitoring tunneling induced ground displacements using distributed fiber-optic sensing. Tunnelling and Underground Space Technology, 40, 141-150

41. Mazek, S. A., \& Almannaei, H. A. (2013). Finite element model of Cairo metro tunnel-Line 3 performance. Ain Shams Engineering Journal, 4(4), 709-716

42. Alielahi, H., \& Adampira, M. (2016). Effect of twin-parallel tunnels on seismic ground response due to vertically in-plane waves. International Journal of Rock Mechanics and Mining Sciences, $85,67-83$

43. Work begins on first two-track line tunnel of prague metro network. Tunnelling and Underground Space Technology, 1996. 11(1): 99-103.

44. Amoun, S., et al. (2017). Evaluation of tool wear in EPB tunneling of Tehran Metro, line 7 expansion. Tunnelling and Underground Space Technology, 61, 233-246

45. Nahvi, A., et al. (2019). Deterministic and stochastic life-cycle cost analysis for Otta seal surface treatment on low volume roads. International Journal of Pavement Research and Technology, 12(1), 101-109

46. Gadsby, A., \& Tsai, J. (2021). Environmental impact comparison of new micro-milling and thin overlay and conventional milling for sustainable pavement preservation. International Journal of Pavement Research and Technology, 14(1), 23-29

47. Kasper, T., \& Meschke, G. (2004). A 3D finite element simulation model for TBM tunnelling in soft ground. International Journal for Numerical and Analytical Methods in Geomechanics, 28(14), 1441-1460

48. Azimi, M., et al. (2017). Fracture analysis of a special cracked lap shear (CLS) specimen with utilization of virtual crack closure technique (VCCT) by finite Element methods. Journal of Failure Analysis and Prevention, 17(2), 304-314

49. Mirjavadi, S. S., Forsat, M., \& Badnava, S. (2019). Nonlinear modeling and dynamic analysis of bioengineering hyper-elastic tubes based on different material models. Biomechanics and Modeling in Mechanobiology, 9, 971-983

50. Azimi, M., Mirjavadi, S. S., \& Asli, S. A. (2016). Investigation of mesh sensitivity influence to determine crack characteristic by finite element methods. Journal of Failure Analysis and Prevention, 16(3), 506-512

51. Taghipoor, M., Tahami, A., \& Forsat, M. (2020). Numerical and laboratory investigation of fatigue prediction models of asphalt containing glass wastes. International Journal of Fatigue, 140, 105819

52. van Dijk, B. F. J., \& Kaalberg, F. J. (1998). 3-D geotechnical model for the North/Southline in Amsterdam. In A. Cividini (Ed.), Application of Numerical Methods to Geotechnical Problems. International Centre for Mechanical Sciences (Courses and Lectures). (Vol. 397)Vienna: Springer.

53. Zhang, Z., et al. (2018). Stability of NATM tunnel faces in soft surrounding rocks. Computers and Geotechnics, 96, 90-102

54. Karami, M. (2020). Assessing the fatigue performance of buton rock asphalt modified mixtures. International Journal of Pavement Research and Technology, 13(5), 536-547

55. Wang, H. N., et al. (2020). Analytical study on interaction between existing and new tunnels parallel excavated in semi-infinite viscoelastic ground. Computers and Geotechnics, 120, 103385

56. Zhang, M., Li, S., \& Li, P. (2020). Numerical analysis of ground displacement and segmental stress and influence of yaw excavation loadings for a curved shield tunnel. Computers and Geotechnics, 118,103325 


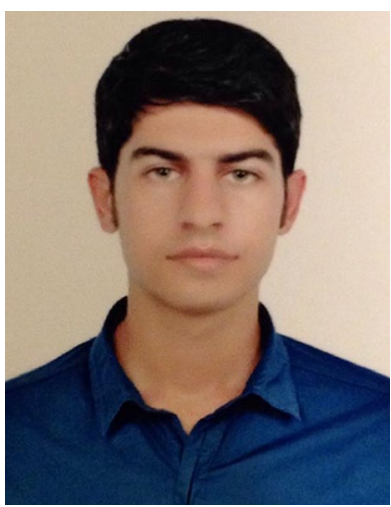

Masoud Forsat obtained $\mathrm{PhD}$ in Civil Engineering at Qatar University. The main research interest of Masoud is on the simulation and modeling using $2 \mathrm{D}$ and 3D finite element methods. His researches are extended to study the fatigue behavior of pavement materials, including asphalt and concrete pavements. He has teaching experience at different universities for more than five years and has published a patent during these years.

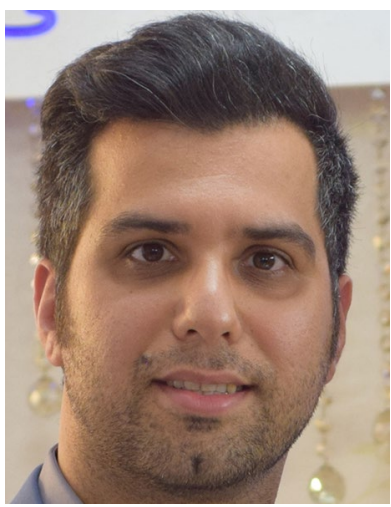

Mohammad Taghipoor is a $\mathrm{PhD}$ graduate at the Tarbiat Modares University, where he is teaching in the Civil Engineering School and the Department of Road and Transportation. Mohammad Taghipoor's research includes the use of new pavement materials in road engineering.

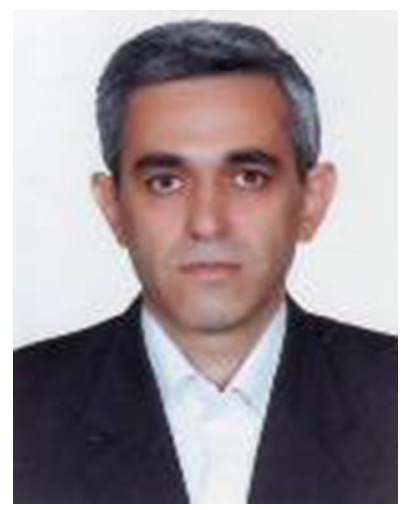

Massoud Palassi is an associate professor at the University of Tehran. He has more than hundreds of research papers and books in his field. Massoud's primary interest is modeling and performance control of tunnels and underground spaces. 